\title{
INVESTIGATION OF HEAVY METAL ADSORPTION ON MICROPLASTICS
}

\author{
OZ, N.* - KADIZADE, G. - YURTSEVER, M. \\ Sakarya University, Engineering Faculty, Sakarya, Turkey \\ (e-mail: goksin.kadizadel@ogr.sakarya.edu.tr;mevci@sakarya.edu.tr \\ phone: +90-264-295-5639; fax: +90-264-295-5601) \\ ${ }^{*}$ Corresponding author \\ e-mail:nuroz@sakarya.edu.tr \\ (Received $5^{\text {th }}$ Feb 2019; accepted $8^{\text {th }}$ Apr 2019)
}

\begin{abstract}
Microplastics and heavy metals represent two pollutant classes which have adverse impacts on aquatic ecosystems. This study has investigated the adsorption of two heavy metals [Lead ( $\mathrm{Pb}) \mathrm{II}$ and Aluminum (Al)III] on three different types of microplastics [polyethylene terephthalate (PET), polyamide (PA), ethylene vinyl acetate (EVA)]. The Scanning Electron Microscope (SEM) analysis has shown that microplastics have different surface characteristics. The effects of parameters such as the $\mathrm{pH}$ of solution, duration of contact, initial concentration and temperature on adsorption capacity have been examined. Experimental results have been applied to the adsorption isotherm models of Langmuir and Freundlich and it has been seen that the Freundlich model has been seen as more suitable than the Langmuir model. Moreover, the pseudo-second kinetic has been found to be more appropriate than the pseudo-first kinetic model. Adsorption percentages have changed according to the type of microplastic and working conditions. Finally, the study has investigated the potential of microplastics to act as an instrument of transport for heavy metals to the food chain and for their bioaccumulation.
\end{abstract}

Keywords: polyethylene terephthalate, polyamide, ethylene vinyl acetate, bioaccumulation

\section{Introduction}

The term microplastic was first used in 2004 to define microscopic plastic particles with a diameter of approximately 20 microns (Thompson et al., 2004). In time, this definition widened to include plastic parts with diameters smaller than $5 \mathrm{~mm}$ (Arthur et al., 2008). Today, it is estimated that there are at least 5.25 trillion microplastics in the seas with a weight of 268,940 tons. Microplastics are generally transported to the seas and oceans by river flows (Okubo et al., 2018). It is thought that $10 \%$ of plastics in the oceans stem from ships and fishing activities. Furthermore, detergents, cleaning agents and cosmetic products contain microplastics as well (Aytan et al., 2016).

It is known that plastic parts in the seas and freshwater ecosystems are divided into tiny particles by small sea creatures. Microplastics can spread widely in water environment through currents and hydrodynamic processes due to their persistent characteristics (Ng and Obbard, 2006). Particles with a high density deposit and accumulate, while low-density particles float on water (Cauwenberghe and Janssen, 2014). Moreover, it is more likely for buoyant particles into be swallowed and transferred to the food chain (Boerger et al., 2010). Micrometer-sized plastic particles are swallowed by sea creatures like fish, worms, sea birds, crustaceans and clams (Hu et al., 2017). This type of feeding might obstruct the gastrointestinal tract, leading to limited nutrition. These particles might even be transferred into the circulation system through intestinal wall. Swallowing microplastics may cause serious harm to vital functions of living creatures (Cauwenberghe and Janssen, 2014). 
Microplastics are potential carriers that can adsorb heavy metals in aquatic environments due to their specific surface areas. It is even possible for heavy metals adsorbed onto microplastics to be transferred to a great variety of aquatic organisms in both seas and freshwaters (Digka et al., 2018). Thus, microplastics have bioaccumulation potential throughout the food chain (Galloway, 2015).

Metal pollution is rather high in seas and freshwaters due to industrial wastes, paints containing metals and fuel combustion (Fu and Wang, 2011; Brennecke et al., 2016; Yousefzadeh et al., 2018). In the same manner, microplastics are known to abound in seas and freshwaters because of human activities (Brennecke et al., 2016). Until recently, interactions between plastics and metals have not been considered important. It is probably thought that polymers are ineffective against metals. However, microplastics are an important intermediary for the transportation of metals in aquatic environments and they display a higher inclination for adsorption of heavy metals in freshwaters (Holmes et al., 2012).

The adsorption of heavy metals by microplastics may differ according to the physical properties of microplastics, the size of pores, surface area and the type of microplastics. Therefore, the type of microplastics is influential on adsorption efficiency. Three different types of microplastics were used in this experimental study, which are polyethylene terephthalate (PET), polyamide (PA) and ethylene vinyl acetate (EVA) found in the sea ecosystem. The aim of this study is to investigate the adsorption of heavy metals onto microplastics.

\section{Material and Methods}

\section{Stock Solutions of Lead and Aluminum Ions}

As the lead stock solution, $1000 \mathrm{mg} / \mathrm{L}$ of $\mathrm{Pb}\left(\mathrm{NO}_{3}\right)_{2}$ (Merck) was used and as the aluminum stock solution, $1000 \mathrm{mg} / \mathrm{L}$ of $\mathrm{Al}\left(\mathrm{NO}_{3}\right)_{3}$ (Merck) was used. Solutions with varying concentrations were prepared with these stock solutions and 1 gr of microplastics was added.

\section{Microplastic Pellets}

PET, PA and EVA were purchased as granules. These granules had sizes of $0.5-1 \mathrm{~mm}$. The morphological features of plastics were examined in the Scanning Electron Microscope (SEM). Figure 1 displays the SEM micrographs of PET, PA and EVA, respectively. As can be seen in Figure 1, the surfaces of microplastics vary according to their type.

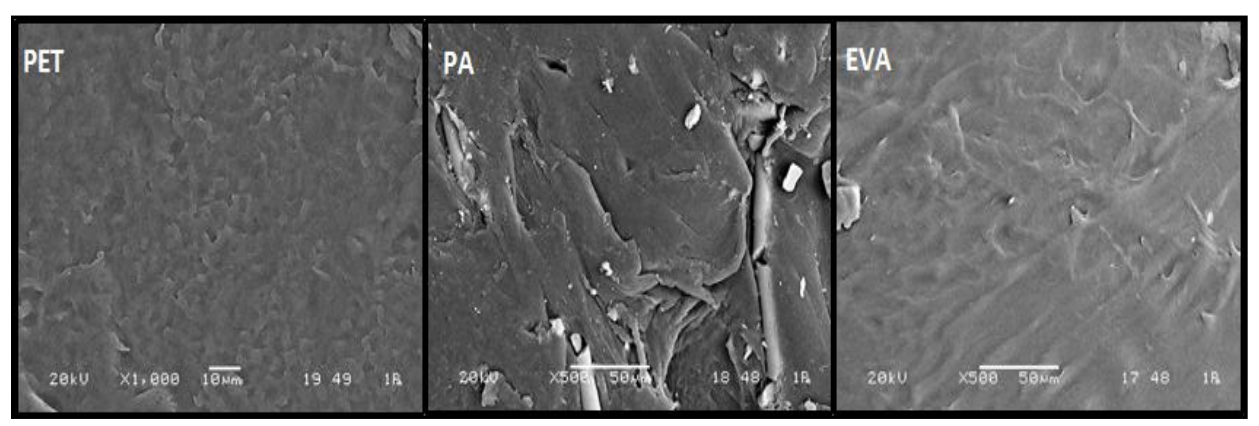

Figure 1. SEM images of PET, $P A$, and EVA raw pellets 


\section{Experimental Study Methods}

This study investigated how the adsorption capacity is affected by $\mathrm{pH}(2,3,4,5,6,7$, $8,9,10)$ duration of contact $(5,15,30,60,90 \mathrm{~min})$, initial concentration $(0.5,1,2,3,4$, $5,6,7 \mathrm{ppm})$ and temperature $\left(25,35,45,55^{\circ} \mathrm{C}\right)$, which are significant parameters in adsorption processes and which affect the solution, and the features of the adsorbent and it was tried to find optimum conditions. A solution volume of $1000 \mathrm{~mL}$ was used in all the adsorption experiments. The $\mathrm{pH}$ adjustment was carried out with $0.1 \mathrm{M} \mathrm{HCl}$ or $\mathrm{NaOH}$ solutions. Solutions with different concentrations were prepared by diluting the standard stock solution of $\mathrm{Pb}$ or A1. The solutions were added with $1 \mathrm{gr}$ of PET, PA and EVA, respectively, and stirred on a magnetic stirrer with a fixed stirring speed of $180 \mathrm{rpm}$. The filtrate water was put into falcon tubes of $50 \mathrm{~mL}$. Three replicates were carried out for each experiment. The concentration of metal in the filtrate was examined with ICP-OES and adsorption removal efficiencies were determined based on the results. The adsorption percentage was calculated based on the Equation 1.

$$
\% \text { Ads }=100-\frac{[\mathrm{A}] \mathrm{r}}{[\mathrm{A}] \mathrm{B}} \times 100
$$

where, \%ads is the adsorption percentage; $[\mathrm{A}]_{t}$ is the concentration of heavy metal remaining in the solution after time $t$; and $[\mathrm{A}]_{0}$ is the concentration of heavy metal at time 0 .

\section{Adsorption models}

The adsorption isotherm models of Langmuir and Freundlich were used in this study. Linear forms of the Langmuir isotherm are shown in Equations 2, 3 and 4:

$$
\begin{gathered}
\mathrm{q}_{\mathrm{a}}=\frac{\mathrm{Q}_{\max } \mathrm{a}_{\mathrm{L}} \mathrm{C}_{\mathrm{a}}}{1+\mathrm{a}_{\mathrm{T}} \mathrm{C}_{\mathrm{s}}} \\
\mathrm{q}_{\mathrm{s}}=\frac{\mathrm{k}_{\mathrm{I}} \mathrm{C}_{\mathrm{a}}}{1+\mathrm{a}_{\mathrm{T}} \mathrm{C}_{\mathrm{s}}}
\end{gathered}
$$

To show this in a linear way;

$$
\frac{1}{\mathrm{q}_{\mathrm{g}}}=\left(\frac{1}{\mathrm{~K}_{\mathrm{L}}}\right) \cdot \frac{1}{\mathrm{C}_{\mathrm{I}}}+\frac{\mathrm{a}_{\mathrm{I}}}{\mathrm{K}_{\mathrm{I}}}
$$

where, $\mathrm{q}_{\max }$ is the single layer capacity of heavy metal $(\mathrm{mg} / \mathrm{g}) ; \mathrm{C}_{\mathrm{e}}$ is the concentration of heavy metal molecules remaining in solution at equilibrium $(\mathrm{mg} / \mathrm{L}) ; \mathrm{K}$ is the Langmuir constant related to the adsorption balance and energy $(\mathrm{L} / \mathrm{mg})$; $\mathrm{a}_{\mathrm{L}}$ is the constant based on adsorption energy $(\mathrm{L} / \mathrm{mg})$; and $\mathrm{q}_{\mathrm{e}}$ is the amount of material adsorbed on unit adsorbent $(\mathrm{mg} / \mathrm{g})$.

When the graph of $\mathrm{C}_{\mathrm{e}} / \mathrm{q}_{\mathrm{e}}$ was drawn against $\mathrm{C}_{\mathrm{e}}$, the curve of the linear graph gives $a_{\mathrm{L}} / \mathrm{K}_{\mathrm{L}}$ and the point where it cuts the $\mathrm{y}$-axis gives $1 / \mathrm{K}_{\mathrm{L}}$. The $\mathrm{R}^{2}$ constant was calculated to find the suitability of adsorption and this constant requires the suitability condition to have values between 0 and 1 (Hamdaoui and Naffrechoux, 2007).

The linear forms of the Freundlich isotherm are shown in the Equations 5 and 6.

$$
\mathrm{qe}=\mathrm{K}_{\mathrm{f}} \mathrm{Ce}^{1 / \mathrm{n}}
$$


where; $\mathrm{C}_{\mathrm{e}}$ is the concentration of the material remaining after adsorption $(\mathrm{mg} / \mathrm{L})$; $\mathrm{q}_{\mathrm{e}}$ is the amount of adsorbed material on unit adsorbent $(\mathrm{mg} / \mathrm{g}) ; \mathrm{K}_{\mathrm{f}}$ is calculated experimentally. Adsorption capacity $(\mathrm{L} / \mathrm{g}) ; \mathrm{n}$ is the heterogeneity factor (without unit).

In the Freundlich isotherm, the logarithm of both sides of the Equation 5 is taken and linearized.

$$
\mathrm{q}_{\mathrm{z}}=\log \mathrm{K}_{\mathrm{f}}+\frac{1}{\mathrm{n}} \log \mathrm{C}_{\mathrm{e}}
$$

The $\mathrm{K}_{\mathrm{f}}$ and $\mathrm{n}$ constants are determined by drawing the change of log $\mathrm{q}_{\mathrm{e}}$ according to $\log \mathrm{C}_{\mathrm{e}}$. The cut off point of the $\mathrm{y}$-axis of the line obtained from the graph gives $\log \mathrm{K}_{\mathrm{f}}$ and its curve 1/n (Aksu and Yener, 2001).

\section{Adsorption Kinetics}

In order to explain the adsorption of heavy metals on any adsorbent, usually the pseudo-first order and pseudo-second order models are used. In the pseudo-first order model of Lagergren, it is seen that a proportional change occurs in time when solid surface is saturated in different concentrations.

The pseudo-first order equation is given with ( $E q .7)$;

$$
\ln (\mathrm{qe}-\mathrm{qt})=\ln \mathrm{qe}-\mathrm{k} 1 \mathrm{t}
$$

where; $\mathrm{q}_{\mathrm{t}}$ is the amount of adsorbate on adsorbent at any time $(\mathrm{mg} / \mathrm{g})$; $\mathrm{k}_{1}$ is the first order kinetic rate constant $\left(\mathrm{min}^{-1}\right)$.

If a graph is drawn between $\ln \left(\mathrm{q}_{\mathrm{e}}-\mathrm{q}_{\mathrm{t}}\right)$ and $\mathrm{t}$, a straight line is obtained. The curve of this line gives the $\mathrm{k}_{1}$ constant and the point where it cuts the $\mathrm{y}$-axis gives the lnqe value (Lagergren, 1898).

The pseudo-second order equation is given with $(E q .8)$;

$$
\frac{t}{q_{1}}=\left[\frac{1}{k_{2} \cdot q_{2}}\right]+\frac{1}{q_{1}} \cdot t
$$

where; $\mathrm{k}_{2}$ is the second order kinetic rate constant is (gr/mg.min).

When a graph is drawn between $t / q_{t}$ and $t$, a straight line is obtained. The curve of this line gives the $1 / \mathrm{q}_{\mathrm{e}}$ value and the point where it cuts the $\mathrm{y}$-axis gives the $1 / \mathrm{k}_{2}$. $\mathrm{qe}_{2}$ value (Ho and Mckay, 1999).

\section{Results and Discussion}

\section{Adsorption Experiments}

The most significant factor in heavy metal adsorption is $\mathrm{pH}$. During the experiments, initially concentration, the duration of contact and temperature were kept constant and $\mathrm{pH}$ values ranging between $2-10$ were used. When heavy metals had a tendency to precipitate at $\mathrm{pH} 6$ or higher, the $\mathrm{pH}$ was determined to be 5.5 .

The optimum $\mathrm{pH}$ was set as 5.5 against the precipitation tendency of heavy metals (Li et al., 2008). $\mathrm{Pb}$ (II) or $\mathrm{Al}(\mathrm{III})$ solutions were studied for 5-90 min in $\mathrm{pH} 5.5$ with a concentration of $1 \mathrm{ppm}$ and it was established that the optimum duration of contact was $60 \mathrm{~min}$. Furthermore, solutions were prepared with a $\mathrm{pH}$ value of 5.5 between the 
ranges of $0.5-7 \mathrm{ppm}$ and stirred at $25^{\circ} \mathrm{C}$ for $60 \mathrm{~min}$ in order to examine the concentration changes of $\mathrm{Pb}$ (II) and $\mathrm{Al}$ (III) ions. At the end of the experiment, it was seen that the optimum concentration was 4 ppm for $\mathrm{Pb}(\mathrm{II})$ and $3 \mathrm{ppm}$ for $\mathrm{Al}(\mathrm{III})$.

The experiment results in Figure 2 and Figure 3 were obtained by working at optimum $\mathrm{pH}$, contact time and initial concentration to investigate the temperature effect of $\mathrm{Pb}$ (II) and $\mathrm{Al}$ (III) ions on adsorption. The highest adsorption capacities were obtained in experiments conducted in optimum conditions with a $\mathrm{pH}$ value of 5.5, an initial concentration of $4 \mathrm{ppm}$, a temperature of $55^{\circ} \mathrm{C}$ and with a 60 -min stirring time.
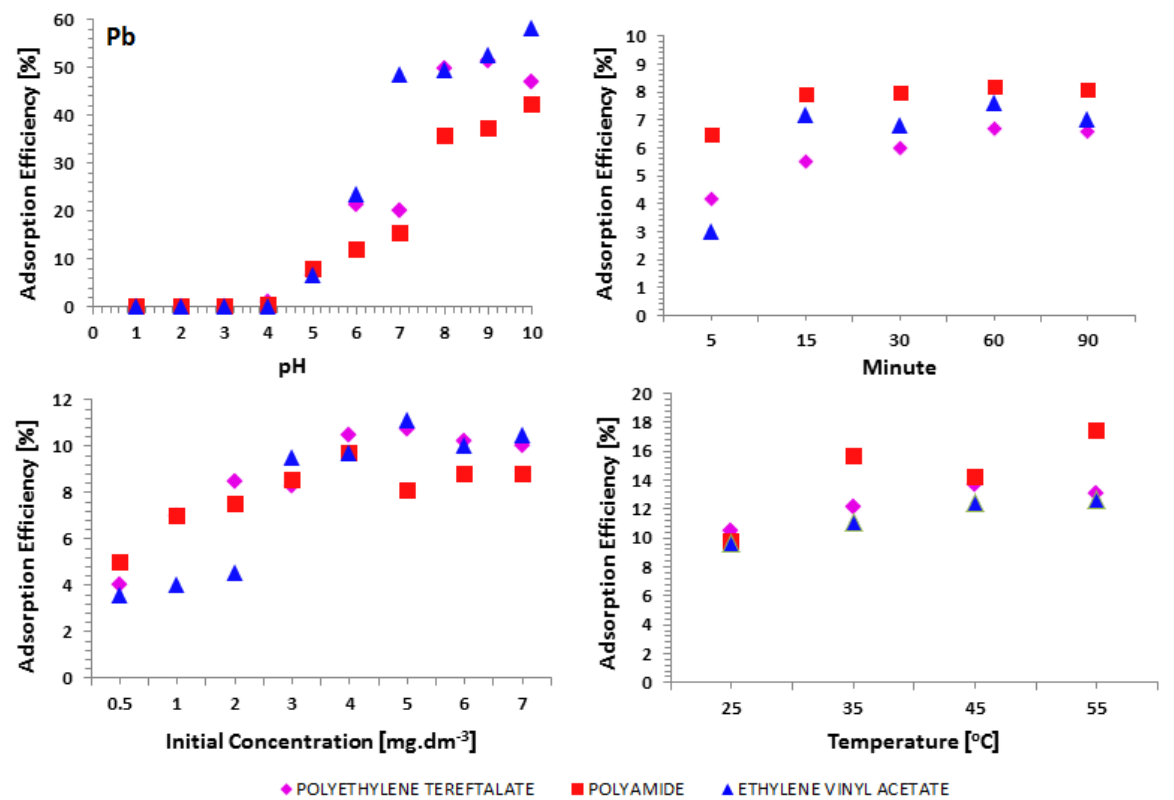

Figure 2. $\mathrm{Pb}(\mathrm{II})$ adsorption temperature ( $\mathrm{pH}: 5.5$, time: $60 \mathrm{~min}$, initial concentration: $4 \mathrm{ppm}$ )
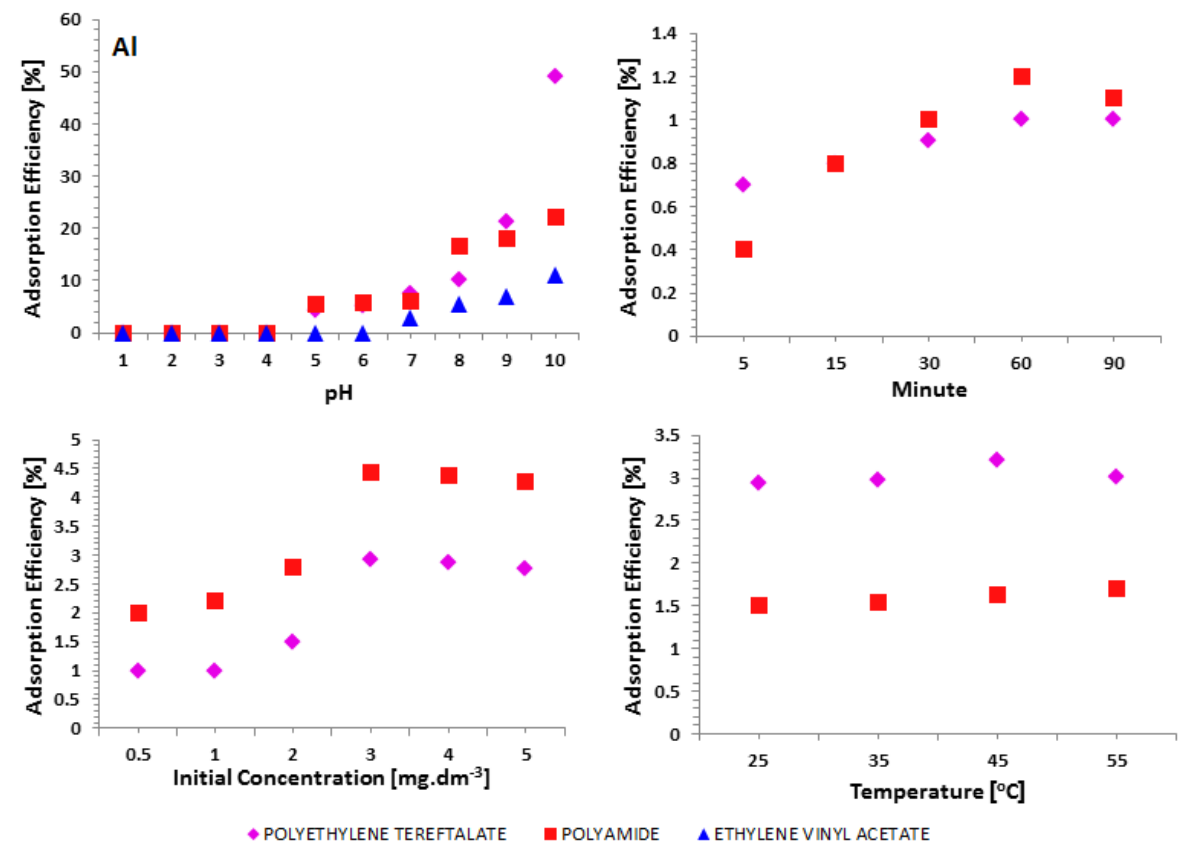

Figure 3. Al (III) adsorption temperature (pH: 5.5, time: 60 min, initial concentration: 3 ppm) 
It is seen in the graph given in Figure 2 that the adsorption capacity increased for PET, PA and EVA with increasing temperatures but it was not affected much. The adsorption capacity also changed based on the type of microplastic. The adsorption capacities were detected as PA, PET, and EVA in the descending order. The high adsorption capacity of PA supports the results of other studies in literature (Wang et al., 2015; Li et al., 2018).

Experiments were repeated for the adsorption of PET, PA and EVA on Al(III) and the adsorption of EVA on Al(III) did not occur in any circumstances. It is seen in the graph given in Figure 3 that the adsorption capacity of PET and PA increased with increasing temperatures but it was not affected much. The adsorption capacity also changed based on the type of microplastic. The adsorption capacity of PET was higher than that of PA in adsorption experiments carried out under the same conditions. The studies suggest that the polarity of MPs can affect the adsorption levels of polar chemicals. Physicochemical properties of MPs may affect the adsorption capacity (Teuten et al., 2009; Wang et al., 2015; Li et al., 2018).

\section{Adsorption isotherm of heavy metals in microplastics}

Experiments for adsorption isotherms were carried out in concentrations of 0.5-1-23-4-5-6-7 $\mathrm{mg} / \mathrm{L}$. When the $\mathrm{R}^{2}$ values of the Langmuir and Freundlich isotherms were studied in experimental results obtained in adsorption equilibrium state for all three microplastics, it was determined that the regression coefficients of the Freundlich isotherm were higher than the Langmuir isotherm and they were more suitable for the Freundlich isotherm (Figure 4). Several studies have reported that the sorption of pollutants on microplastics fit well with Freundlich model (Razanajatovo et al., 2018; Zhang et al., 2018; Llorca et al., 2018; Wu et al., 2019). This indicates that the relationship between microplastics and heavy metals is multi-layer adsorption on heterogeneous surfaces (Andersson et al., 2011).
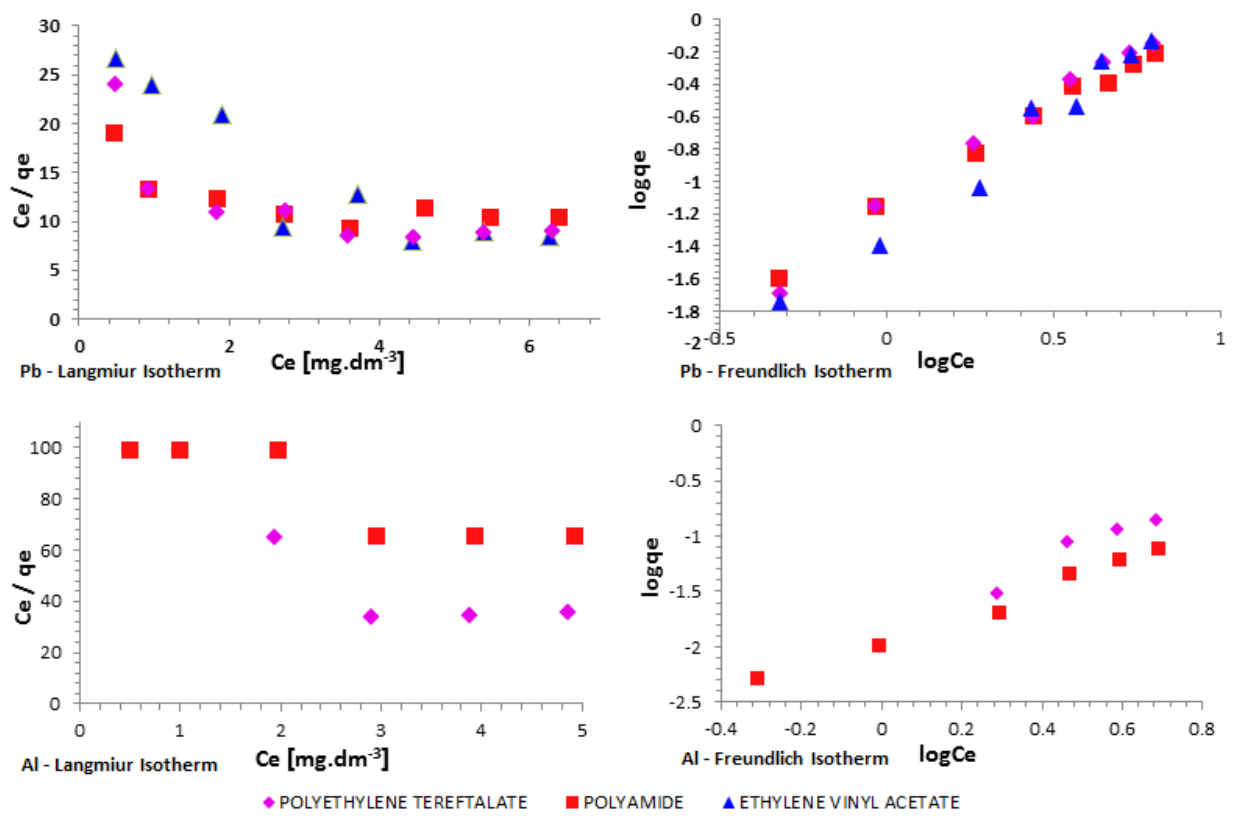

Figure 4. Adsorption isotherms of Pb(II) and Al(III) onto PET, PA, EVA 
The balance data obtained were applied to the Freundlich and Langmuir models, which are widely used to explain the adsorption process, and the constants of both isotherms were calculated. The predicted Langmuir and Freundlich constants are summarized in Table 1 and Table 2.

Table 1. Parameters of Langmuir and Freundlich isotherms for Pb(II) adsorption

\begin{tabular}{c|c|c|c|c|c|c}
\hline Pb & \multicolumn{2}{|c|}{ Langmuir Isotherm Constants } & \multicolumn{3}{c}{ Freundlich Isotherm Constants } \\
\hline & $\mathrm{q}_{\max }(\mathrm{mg} / \mathrm{gr})$ & $\mathrm{K}_{\mathrm{L}}(\mathrm{L} / \mathrm{mg})$ & $\mathrm{R}^{2}$ & $\mathrm{~K}_{\mathrm{f}}(\mathrm{mg} / \mathrm{gr})$ & $\mathrm{n}$ & $\mathrm{R}^{2}$ \\
\hline PET & -0.551 & -0.103 & 0.526 & 0.065 & 0.733 & 0.988 \\
PA & -0.978 & -0.065 & 0.513 & 0.069 & 0.822 & 0.991 \\
EVA & -0.303 & -0.128 & 0.791 & 0.047 & 0.661 & 0.978 \\
\hline
\end{tabular}

Table 2. Parameters of Langmuir and Freundlich isotherms for Al(III) adsorption

\begin{tabular}{c|c|c|c|c|c|c}
\hline Al & \multicolumn{3}{|c|}{ Langmuir Isotherm Constants } & \multicolumn{3}{c}{ Freundlich Isotherm Constants } \\
\hline & $\mathrm{q} \max (\mathrm{mg} / \mathrm{gr})$ & $\mathrm{K}_{\mathrm{L}}(\mathrm{L} / \mathrm{mg})$ & $\mathrm{R}^{2}$ & $\mathrm{~K}_{\mathrm{f}}(\mathrm{mg} / \mathrm{gr})$ & $\mathrm{n}$ & $\mathrm{R}^{2}$ \\
\hline PET & -0.058 & -0.165 & 0.831 & 0.012 & 0.64 & 0.98 \\
PA & -0.105 & -0.089 & 0.79 & 0.01 & 0.821 & 0.987 \\
\hline
\end{tabular}

\section{Adsorption Kinetic of Microplastics and Heavy Metals}

Adsorption kinetics is important when assessing adsorption efficiency. The kinetic study was conducted in order to understand the time-dependent behavior of heavy metal adsorption on microplastics. Adsorption capacities $\left(\mathrm{q}_{\mathrm{e}}\right)$ and adsorption rate constants $\left(\mathrm{k}_{1}\right.$ and $\mathrm{k}_{2}$ ) were calculated using the curve values of the lines in the graphs which were drawn by calculating the values corresponding to different adsorption durations $(t)$ and given in Figure 5. For $\mathrm{Pb}(\mathrm{II})$ and $\mathrm{Al}(\mathrm{III})$, the adsorption efficiency in the first $60 \mathrm{~min}$ after adsorption experiments began and later it reached adsorption equilibrium and slowed down. Based on these results, a contact duration of 60 min was selected.
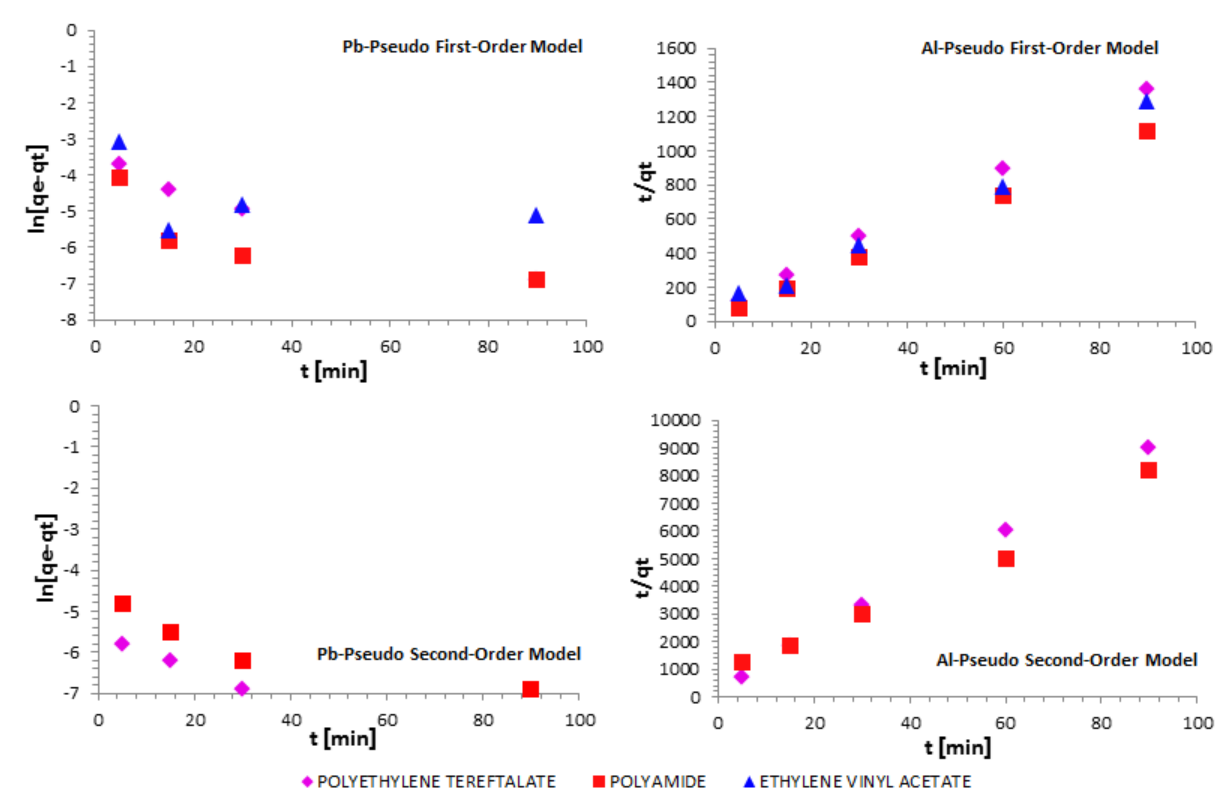

Figure 5. Pseudo-first order and pseudo-second order kinetic models for Pb(II) and Al(III) 
The pseudo-first and pseudo-second order models determine the adsorption rate. While the adsorption rate is a physical process for the pseudo-first order model, it is a chemical process for the pseudo-second order model involving the adsorbent force (Mohan et al., 2006). Therefore, the data in the kinetic study in Figure 5 were applied to the pseudo-first and pseudo-second order models to investigate rate limiting mechanisms. The results of the pseudo-first and pseudo-second order models are summarized in Table 3 and Table 4 including parameters like $\mathrm{k}_{1}$ and $\mathrm{k}_{2}$ and experimental $\left(q_{e, \exp }\right)$. For both metals $\left(\mathrm{q}_{e, \text { cal }}\right)$, the values of the balance adsorption amount and the correlation coefficient $\left(\mathrm{R}^{2}\right)$ are suitable with the pseudo-second order model, which is higher than the pseudo-first order model.

Table 3. Parameters of pseudo-first order and pseudo-second order kinetic models for Pb(II)

\begin{tabular}{c|cc|ccc|ccc}
\hline Pb & & & \multicolumn{3}{|c|}{$\begin{array}{c}\text { pseudo first-order } \\
\text { (PFO) }\end{array}$} & \multicolumn{3}{c}{$\begin{array}{c}\text { pseudo second-order } \\
\text { (PSO) }\end{array}$} \\
\hline & $\begin{array}{c}\mathrm{Co} \\
(\mathrm{mg} / \mathrm{L})\end{array}$ & $\begin{array}{c}\mathrm{q}_{\mathrm{e} e \mathrm{exp}} \\
(\mathrm{mg} / \mathrm{gr})\end{array}$ & $\begin{array}{c}\mathrm{k}_{1} \\
(1 / \mathrm{min})\end{array}$ & $\begin{array}{c}\mathrm{q}_{\mathrm{e}, \mathrm{cal}} \\
(\mathrm{mg} / \mathrm{gr})\end{array}$ & $\mathrm{R}^{2}$ & $\begin{array}{c}\mathrm{k}_{2} \\
(\mathrm{gr} / \mathrm{mg} . \mathrm{min})\end{array}$ & $\begin{array}{c}\mathrm{q}_{\mathrm{e}, \mathrm{cal}} \\
(\mathrm{mg} / \mathrm{gr})\end{array}$ & $\mathrm{R}^{2}$ \\
\hline PET & 1 & 0.067 & 0.035 & 0.023 & 0.982 & 4.03 & 0.069 & 0.999 \\
PA & 1 & 0.082 & 0.0254 & 0.007 & 0.642 & 14.49 & 0.082 & 0.999 \\
EVA & 1 & 0.076 & 0.0125 & 0.015 & 0.196 & 3.937 & 0.075 & 0.989 \\
\hline
\end{tabular}

Table 4. Parameters of pseudo-first-order and pseudo-second-order kinetic models for Al(III)

\begin{tabular}{|c|c|c|c|c|c|c|c|c|}
\hline \multirow[t]{2}{*}{$\mathbf{P b}$} & & & \multicolumn{3}{|c|}{$\begin{array}{l}\text { pseudo first-order } \\
\text { (PFO) }\end{array}$} & \multicolumn{3}{|c|}{$\begin{array}{c}\text { pseudo second-order } \\
\text { (PSO) }\end{array}$} \\
\hline & $\begin{array}{c}\mathrm{Co} \\
(\mathrm{mg} / \mathrm{L})\end{array}$ & $\begin{array}{l}\mathrm{q} \text { e }, \exp \\
(\mathrm{mg} / \mathrm{gr})\end{array}$ & $\begin{array}{c}\mathrm{k}_{1} \\
(1 / \mathrm{min})\end{array}$ & $\begin{array}{l}\mathrm{q} \text { e }, \mathrm{cal} \\
(\mathrm{mg} / \mathrm{gr})\end{array}$ & $\mathrm{R}^{2}$ & $\begin{array}{c}\mathrm{k} 2 \\
(\mathrm{gr} / \mathrm{mg} \cdot \mathrm{min})\end{array}$ & $\begin{array}{c}\mathrm{q} \text { e,cal } \\
(\mathrm{mg} / \mathrm{gr})\end{array}$ & $\mathrm{R}^{2}$ \\
\hline PET & 1 & 0.01 & 0.044 & 0.003 & 0.998 & 26.385 & 0.01 & 0.999 \\
\hline PA & 1 & 0.012 & 0.021 & 0.006 & 0.837 & 9.765 & 0.012 & 0.988 \\
\hline
\end{tabular}

\section{Conclusion}

Microplastics and heavy metals are sources of pollution in sea and freshwater ecosystems. The interaction between these two pollutants may create a serious problem to aquatic ecosystems. This study investigated the role of PA, PET and EVA in the transport of the heavy metals of $\mathrm{Pb}$ and $\mathrm{Al}$ to the food chain and in their bioaccumulation.

The adsorption behaviors of 2 heavy metals on 3 types of microplastic pellets were carefully evaluated. Our results showed that adsorption capacities varied among heavy metals, plastic types, and environmental conditions (e.g., pH). Overall, the adsorption percentage in the study was low. In addition, literature studies, laboratory tests and environmental monitoring using plastic pellets have shown that plastics can accumulate metals (Wang et al., 2017). Heavy metals and persistent organic pollutants enter into the food chain and bioaccumulation may occur in living things that swallow these microplastics (Wang et al., 2016). Because of the abundance of plastics in aquatic ecosystem their role in respect of bioaccumulation of a broader range of contaminants merits further study. 
Acknowledgements. This research work was supported and granted by the Graduate School of Scientific Research, Project Commission (Proje no: 2017-50-01-069) of Sakarya University.

\section{REFERENCES}

[1] Aksu, Z., Yener, J. (2001): A comperative adsorption/biosorption study of monochlorinated phenols onto various sorbents. - Waste Management 21: 695-702.

[2] Andersson, K. I., Eriksson, M., Norgren, M. (2011): Removal of lignin from wastewater generated by mechanical pulping using activated carbon and fly ash: adsorption isotherms and thermodynamics. - Ind. Eng. Chem. Res 50: 7722-7732.

[3] Arthur, C., Baker, J., Bamford, H. (eds.) (2008): Proceedings of the International Research Workshop on the Occurrence, Effects and Fate of Micro-plastic Marine Debris. - NOAA Technical Memorandum NOS-OR\&R-30, USA.

[4] Aytan, U., Valente, A., Senturk, Y., Usta, R., Sahin, F. B. E., Mazlum, R. E., Agirbas, E. (2016): First evaluation of neustonic microplastics in Black Sea waters. - Marine Environmental Research 119: 22-30.

[5] Boerger, C. M., Lattin, G. L., Moore, S. L., Moore, C. J. (2010): Plastic ingestion by planktivorous fishes in the North Pacific Central Gyre. - Marine Pollution Bulletin 60: 2275-2278.

[6] Brennecke, D., Duarte, B., Paiva, F., Caçador, I., Clode, J. (2016): Microplastics as vector for heavy metal contamination from the marine environment. - Estuarine, Coastal and Shelf Science 178: 189-195.

[7] Cauwenberghe, L. V., Janssen, C. R. (2014): Microplastics in bivalves cultured for human consumption. - Environmental Pollution 193: 65-70.

[8] Digka, N., Tsangaris, C., Torre, M., Anastasopoulou, A., Zeri, C. (2018): Microplastics in mussels and fish from the Northern Ionian Sea. - Marine Pollution Bulletin135: 30-40.

[9] Fu, F., Wang, Q. (2011): Removal of heavy metal ions from wastewaters: A review. Journal of Environmental Management 92: 407-418.

[10] Galloway, T. S. (2015): Micro- and nano-plastics and human health. - In: Bergmann, M., Gutow, L., Klages, M. (eds.) Marine Anthropogenic Litter. Springer International Publishing: 343-366.

[11] Hamdaoui, O., Naffrechoux, E. (2007): Modeling of adsorption isotherms of phenol and chlorophenols onto granular activated carbon: Part I. Two-parameter models and equations allowing determination of thermodynamic parameters. - Journal of Hazardous Materials 147: 381-394.

[12] Ho, Y. S., Mckay, G. (1999): Pseudo-second order model for sorption processes. Process Biochemistry 34: 451-465.

[13] Holmes, L. A., Turner, A., Thompson, R. C. (2012): Adsorption of trace metals to plastic resin pellets in the marine environment. - Environmental Pollution 160: 42-48.

[14] Hu, J. Q., Yang, S. Z., Guo, L., Xu, X., Yao, T., Xie, F. (2017): Microscopic investigation on the adsorption of lubrication oil on microplastics. - Journal of Molecular Liquids 227: 351-355

[15] Lagergren, S. (1898): Zur theorie der sogenannten adsorption gelöster stoffe, Kungliga Svenska Vetenskapsakademiens. - Handlingar 24: 1-39.

[16] Li, W., Zhang, L., Peng, J., Li, N., Zhang, S., Guo, S. (2008): Tobacco stems as a low cost adsorbent for the removal of $\mathrm{Pb}(\mathrm{II})$ from wastewater: Equilibrium and kinetic studies. - Industrial Crops and Products 28: 294-302.

[17] Li, J., Zhang, K., Zhang, H. (2018): Adsorption of antibiotics on microplastics. Environmental Pollution 237: 460-467.

[18] Llorca, M., Schirinzi, G., Martínez, M., Barcelo, D., Farre, M. (2018): Adsorption of perfluoroalkyl substances on microplastics under environmental conditions. Environmental Pollution 235: 680-691. 
[19] Mohan, D., Singh, K. P., Singh, V. K. (2006): Trivalent chromium removal from wastewater using low cost activated carbon derived from agricultural waste material and activated carbon fabric cloth. - Journal of Hazardous Materials 135: 280-295.

[20] Ng, K. L., Obbard, J. P. (2006): Prevalence of microplastics in Singapore's coastal marine environment. - Marine Pollution Bulletin 52: 761-767.

[21] Okubo, N., Takahashi, S., Nakano, Y. (2018): Microplastics disturb the anthozoan-algae symbiotic relationship. - Marine Pollution Bulletin 135: 83-89.

[22] Razanajatovoa, R. M., Dinga, J., Zhanga, S., Jianga, H., Zoua, H. (2018): Sorption and desorption of selected pharmaceuticals by polyethylene microplastics. - Marine Pollution Bulletin 136: 516-523.

[23] Teuten, E. L., Saquing, J. M., Knappe, D. R. U., Barlaz, M. A., Jonsson, S., Bjorn, A., Rowland, S. J., Thompson, R. C., Galloway, T. S., Yamashita, R., Ochi, D., Watanuki, Y., Moore, C., Hung, P. V., Tana, T. S., Prudente, M., Boonyatumanond, R., Zakaria, M. P., Akkhavong, K., Ogata, Y., Hirai, H., Iwasa, S., Mizukawa, K., Hagino, Y., Imamura, A., Saha, M., Takada, H. (2009): Transport and release of chemicals from plastics to the environment and to wildlife. - Philos. Trans. R. Soc. B 364: 2027-2045.

[24] Thompson, R. C., Olsen, Y., Mitchell, R. P., Davis, A., Rowland, S. J., John, W. G., McGonicle, D., Russell, A. E. (2004): Lost at sea: where is all the plastic? - Science 304: 838.

[25] Wang, F., Shih, K. M., Li, X. Y. (2015): The partition behavior of perfluorooctanesulfonate (PFOS) and perfluorooctanesulfonamide (FOSA) on microplastics. - Chemosphere 119: 841-847.

[26] Wang, J., Tan, Z., Peng, J., Qiu, Q., Li, M. (2016): The behaviors of microplastics in the marine environment. - Mar. Environ. Res 113: 7-17.

[27] Wang, J., Peng, J., Tan, Z., Gao, Y., Zhan, Z., Chen, Q., Cai, L. (2017): Microplastics in the surface sediments from the Beijiang River littoral zone: Composition, abundance, surface textures and interaction with heavy metals. - Chemosphere 171: 248-258.

[28] Wu, P., Cai, Z., Jin, H., Tang, Y. (2019): Adsorption mechanisms of five bisphenol analogues on PVC microplastics. - Science of the Total Environment 650: 671-678.

[29] Yousefzadeh, H., Salarian, A. A., Kalal, H. S. (2018): Study of Pb (II) adsorption from aqueous solutions by $\mathrm{TiO} 2$ functionalized with hydroxide ethyl aniline (PHEA/n-TiO2). Journal of Molecular Liquids 263: 294-302.

[30] Zhang, H., Wang, J., Zhou, B., Zhou, Y., Dai, Z., Zhou, Q., Chriestie, P., Luo Y. (2018): Enhanced adsorption of oxytetracycline to weathered microplastic polystyrene: Kinetics, isotherms and influencing factors. - Environmental Pollution 243: 1550-1557. 